\title{
False-positive lung positron emission tomography- computed tomography result in a patient with a history of cancer
}

\author{
Joanna Chrąchol ${ }^{1}$, Bartosz Kubisa², Paweł Dec ${ }^{3}$, Anna Lesińska ${ }^{4}$, Piotr Waloszczyk ${ }^{5}$, Tomasz Grodzki² \\ ${ }^{1}$ Student Scientific Club at the Department of Thoracic Surgery and Transplantation, Pomeranian Medical University, Szczecin, \\ Poland \\ ${ }^{2}$ Department of Thoracic Surgery and Transplantation, Pomeranian Medical University, Szczecin, Poland \\ ${ }^{3}$ Department of General and Hand Surgery, Pomeranian Medical University, Szczecin, Poland \\ ${ }^{4}$ Department of Invasive Cardiology, District Hospital, Szczecin, Poland \\ ${ }^{5}$ Department od Patomorfology, Prof. A. Sokołowski Regional Pulmonary Hospital, Szczecin-Zdunowo, Poland
}

Kardiochirurgia i Torakochirurgia Polska 2017; 14 (3): 206-208

Chemical pleurodesis is an intrapleural administration of an sclerosing agent - talc, doxycycline or bleomycin. Talc is commonly used due to its high efficiency and low cost; in this form it is known as talc poudrage. This procedure is often used for patients with symptomatic pleural effusion associated, among other things, with cancer, and more rarely in recurrent spontaneous pneumothorax. Its aim is to induce a strong inflammatory response through mechanical and chemical irritation of the pleura and, consequently, to achieve symphysis between the two layers of pleura by sclerosing agents. However, talc is not metabolized by the tissues. Control imaging can imitate tumor growth, often giving false positive results in test interpretations if there are no notes recording this treatment.

The 56-year-old patient was admitted to the Pneumology Department of a local hospital with exertional dyspnea

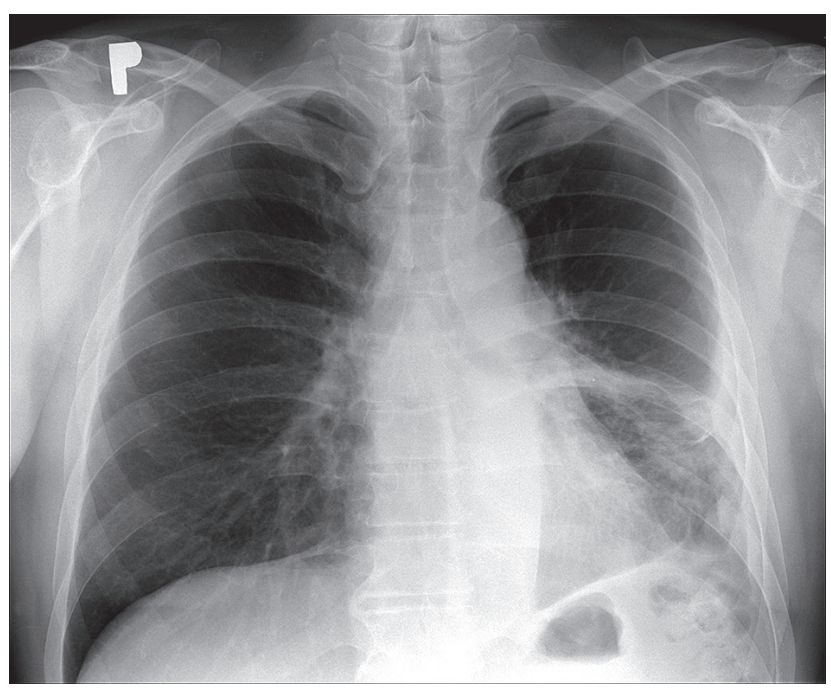

Fig. 1. Chest X-ray and the presence of fluid in the left pleural cavity which required further diagnosis and treatment. A chest X-ray showed an arched shaded left lung to the height of the front section of the fourth rib; above the shadowing, there was slight haze merging with the left niche; the right lung did not represent infiltrated or focal changes (Fig. 1). Bronchofiberoscopy showed evidence of a closure of the ostium of the lower left bronchial lobe by a hypertrophic change, partially covered with necrosis. The process also affected the lower spur. On the right side, all bronchial ostia were found to be clear of any pathological change. Scraps of bronchial tissue showed squamous cell carcinoma in a histopathological diagnosis. An ultrasound of the pleural cavity showed a large amount of fluid in the left pleural cavity. After an oncological consultation, initial chemotherapy (300 mg of paclitaxel and $600 \mathrm{mg}$ of carboplatin) in four cycles every 3 weeks and radiation of $54 \mathrm{~Gy}$ to the mediastinum and 66 Gy to the tumor area and hilum was carried out. Four months after the end of cancer treatment, control positron emission tomography combined with computed X-ray tomography (PET-CT) revealed the presence of numerous atelectases in the middle of the left lung from the hilum to the back chest wall, showing metabolic impulse of SUV 3.66 (standardized uptake value). The left costophrenic angle showed areas of partially calcified clumps measuring $17 \times 40 \mathrm{~mm}$ of SUV 10.57 adjacent to the lateral chest wall, from which a strip of thickened calcified pleura with excessive site reaction of SUV 5.8 stretched cranially. A fiberoptic bronchoscopy confirmed a clear ostium of the right main bronchus. An image of the left main bronchus previously thought to have hyperplastic change was not confirmed. Due to the suspicion of cancer recurrence it was decided to admit the patient to the Department of Thoracic Surgery and Transplantation in order to expand diagnostics and decide whether surgery would be necessary. On admission, the patient was

Address for correspondence: Joanna Chrąchol, Student Scientific Club at the Department of Thoracic Surgery and Transplantation, Pomeranian Medical University, 11 A. Sokołowskiego St, 70-891 Szczecin, Poland, phone: +48 665 754 065, e-mail: j.chrachol@gmail.com Received: 16.01.2017, accepted: 25.05.2017. 
in good general condition, but complained of shortness of breath on exertion, without hemoptysis or weight loss. There were no significant deviations in blood tests. Chest computed tomography described parahilum nodular infiltration on the left side in connection with thickened pleura, which showed contrast enhancement (Fig. 2). Mediastinal lymph nodes were not enlarged. On the left parahilum side there were cirrhotic changes with bronchiectasis, probably the result of previous radiation therapy. At the lingular segment level, nodular infiltrate with dimensions of approx. $3 \times 2.5 \mathrm{~cm}$ was visible in communication with thickened pleura, reinforcing itself after administration of contrast up to 308 Hounsfield units. The right lung showed no pathological changes. Ultrasound imaging of the mediastinum and both pleural cavities did not show any pathology, with the exception of pleural adhesions on the left. The patient was qualified for surgery. Left-sided thoracotomy was performed with the aim of a resection of the change identified in the left lung during the positron emission tomography (PET) test. A intraoperatively wall tumor of $20 \times 40 \mathrm{~mm}$ was found at intercostal space VII in the anterior axillary line forming a concretion of the lower lobe of the left lung. The change was dissected sharply and removed. Cutting the change showed talc plaque. There were no significant early postoperative complications. The patient was discharged in good general condition on the $7^{\text {th }}$ day after hospitalization. The histopathological image responded to the diagnosis of reaction resorption change after talc poudrage. During reexamination of the patient's medical record no information about past talc poudrage was found. The treatment was not described in documentation, possibly by human error. It was probably applied when installing a drain into the left pleural cavity due to a large amount of fluid and then forgotten, not being noted in the patient's summary.

This case shows how important scrupulous documentation can be, as well as detailed analysis of past diseases and treatments, especially in the context of an interpretation of image tests, including those based on tissue metabolism, such as PET. Some authors believe that a combination of PET and computed tomography (CT) tests enables false-positive results to be avoided, but it is not always sufficient. Positron emission tomography is a functional diagnostic test, involving the imaging of tissues and organs, during which a labeled positron-emitting radionuclide (tracer) is introduced (mostly 18-fluorodeoxyglucose - FDG) and accumulates in cells in proportion to the extent of compound metabolism. To determine and compare the intensity of tracer accumulation in different areas of the body, indicator SUV is used, describing the activity of the positron-emitting radionuclide within the examined tissue, divided by background uptake and adjusted for body weight and administered activity. The cut-off point between benign and malignant is the average value of SUV (SUV mean 2.5). Within tumor cells, higher accumulation of FDG is observed than that in adjacent healthy cells. In most cases they occur in the PET as "hot" tissue; however, normal tissue with high metabolic turnover can also have

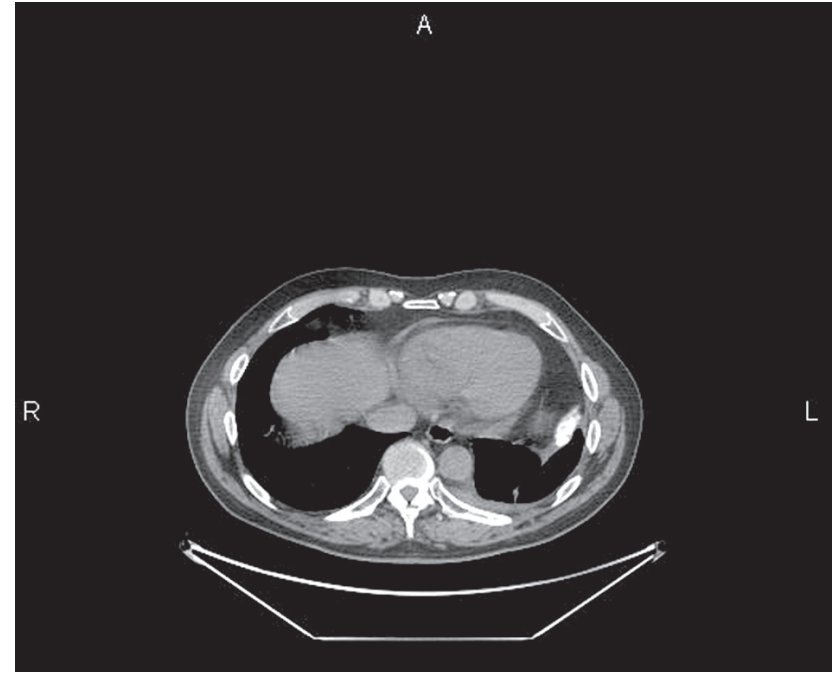

Fig. 2. Contrast-enhanced computed tomography

a value of approximately 10-15. Activated inflammatory cells (neutrophils, fibroblasts, macrophages, lymphocytes) have increased uptake of FDG, which causes problem when differentiating between inflammatory changes and cancer. Also in tuberculosis, sarcoidosis and other granulomatous diseases, lung changes may have an SUV of above 20. It is also significant that, in a short period after the application of white blood cell growth factors, there is intense physiological FDG uptake within bone marrow. All of these clinical situations can cause false positive PET results. The first reports of false-positive findings in PET after earlier talc poudrage were described by Murray et al., in 1997 [1]. Since then, a few works with similar descriptions have been published. Weiss et al. [2] presented a description of a patient with a history of cancer, in whom talc poudrage was performed due to chylothorax, with observed enhanced uptake of glucose in PET-CT and concomitant with that image areas of increased density in $\mathrm{CT}$, recognized as deposits of sclerosing agent after talcing. A similar case was described by Ahmadzadehfar et al. [3], where false positive changes in PET-CT 5 years after talc poudrage with SUV between 2.0 and 16.3 were observed, explaining that the source of false-positive PET-CT findings may be other inflammatory processes, e.g. granulomas, tuberculosis, aspergillosis and nocardiosis. He emphasizes that combination of PET and CT does not always solve the problem of differentiation between any observed changes. Peek et al. [4] described 2 patients in whom, 10 and 11 years earlier, talc poudrage was performed and later, as in previous cases, thickened pleura in CT and corresponding points of increased uptake of glucose in PET were found. In both cases control CT did not show any progression. De Campos et al. [5] presented 15 years of experience with talc poudrage treatment in their work. The most common complications mentioned by the authors include the need for greater retention of drains in the pleural cavity (due to leakage of air or an amount of fluid in excess of $100 \mathrm{ml} / 24 \mathrm{~h}$ ), pleural empyema or fever, and - most dangerously - acute respiratory distress syn- 
drome. Despite this, the current authors wish to emphasize the procedure's high efficiency and the need for another method of pleurodesis. Nguyen et al. [6] reported that talc poudrage causes a significant increase in glucose uptake in PET during the first 3-6 months after treatment, correlating with thickening of pleura visible in CT. After that time, the thickness of pleura is not significantly increased and SUV may remain unchanged or increase further. Vandemoortele et al. [7] described three cases of patients with talc poudrage in an interview; in each there were areas of thickened pleura in CT and a corresponding space of increased uptake of FDG in PET with SUV values of 11, 8 and 9. In 2 cases prior exposure to asbestos in the patients was found. Patients with significant exposure to asbestos are at risk of pleural mesothelioma. In these patients, changes in CT or PET should undergo biopsy, particularly if they experience chest pain. The authors of this paper also stress the importance of interviewing, which might refer to the past treatment of patients with pleural changes and can inform the practitioner of possible false-positive results.

The present case shows the need for accurate descriptions of medical procedures, especially in patients with previous oncology treatment. A knowledge of a patient's medical history can have a marked effect on the interpretation of diagnostic tests and determine the choice of therapeutic intervention. If the results of PET are probably false positive, it seems most appropriate to recommend a CT inspection to determine any possible progression or changes. Such a procedure may prevent unnecessary operations.

\section{Disclosure}

Authors report no conflict of interest.

\section{References}

1. Murray JG, Erasmus JJ, Bahtiarian EA, Goodman PC. Talc pleurodesis simulating pleural metastases on 18F-fluorodeoxyglucose positron emission tomography. AJR Am J Roentgenol 1997; 168: 359-360.

2. Weiss N, Solomon SB. Talc pleurodesis mimics pleural metastases: differentiation with positron emission tomography/computed tomography. Clin Nucl Med 2003; 28: 811-814

3. Ahmadzadehfar H, Palmedo H, Strunk H, Biersack HJ, Habibi E, Ezziddin S. False positive 18F-FDG-PET/CT in a patient after talc pleurodesis. Lung Cancer 2007; 58: 418-421.

4. Peek H, Van der Bruggen W, Limonard G. Pleural FDG uptake more than a decade after talc pleurodesis. Case Rep Med 2009; 2009: 650864.

5. De Campos JR, Vargas FS, De Campos Werebe E, Cardoso P, Teixeira LR, Jatene FB, Light RW. Thoracoscopy talc poudrage: a 15-year experience. Chest 2001; 119: 801-806.

6. Nguyen NC, Tran I, Hueser CN, Oliver D, Farghaly HR, Osman MM. F-18 FDG $\mathrm{PET} / \mathrm{CT}$ characterization of talc pleurodesis-induced pleural changes over time: a retrospective study. Clin Nucl Med 2009; 34: 886-890.

7. Vandemoortele T, Laroumagne S, Roca E, Bylicki O, Dales JP, Dutau H, Astoul P. Positive FDG-PET/CT of the pleura twenty years after talc pleurodesis: three cases of benign talcoma. Respiration 2014; 87: 243-248. 